\title{
Adipocyte extracellular matrix composition, dynamics and role in obesity
}

\author{
Edwin C. M. Mariman • Ping Wang
}

Received: 20 November 2009/Revised: 5 January 2010/Accepted: 7 January 2010/Published online: 27 January 2010

(C) The Author(s) 2010. This article is published with open access at Springerlink.com

\begin{abstract}
The central role of the adipose tissue in lipid metabolism places specific demands on the cell structure of adipocytes. The protein composition and dynamics of the extracellular matrix (ECM) is of crucial importance for the functioning of those cells. Adipogenesis is a bi-phasic process in which the ECM develops from a fibrillar to a laminar structure as cells move from the commitment phase to the growth phase characterized by storage of vast amounts of triglycerides. Mature adipocytes appear to spend a lot of energy on the maintenance of the ECM. ECM remodeling is mediated by a balanced complement of constructive and destructive enzymes together with their enhancers and inhibitors. ECM remodeling is an energy costing process regulated by insulin, by the energy metabolism, and by mechanical forces. In the obese, overgrowth of adipocytes may lead to instability of the ECM, possibly mediated by hypoxia.
\end{abstract}

Keywords Adipocytes - Extracellular matrix · Proteomics · Dynamics · Lipid metabolism · Obesity · Hypoxia

\section{Introduction}

The global rise of overweight and obesity with the risk for complications like type II diabetes and cardiovascular disorders has intensified the attention on the metabolic and

E. C. M. Mariman $(\bowtie) \cdot$ P. Wang Department of Human Biology, NUTRIM School for Nutrition, Toxicology and Metabolism, Maastricht University, P.O. Box 616, 6200 MD Maastricht, The Netherlands e-mail: e.mariman@hb.unimaas.nl physiologic role of the adipose tissue. The major functions of adipose tissue are:

- site for energy storage

- endocrine/paracrine regulator of energy metabolism

- thermal insulation of the body

- shock cushion to protect organs from mechanical damage

Those functions place specific demands on the adipose tissue with respect to its structure and composition. Here, we review various aspects of the adipocyte extracellular matrix (ECM) including its components, development, regulation, and relation to obesity.

Adipose tissue is histologically categorized as a type of loose connective tissue and, as such, collagen contributes considerably to the non-cell mass of this tissue. At least partly, this collagen is produced by the adipocytes, but cells of the stromal vascular fraction containing preadipocytes, capillary endothelial cells, infiltrated monocytes/macrophages, and a population of multipotent stem cells can also contribute to it. It was reported that each adipocyte is surrounded by a thick ECM referred to as basal lamina containing collagen IV as a major component [1]. This characteristic is shared with cells of bone and cartilage, which is not surprising since adipocytes, osteoblasts, and chondrocytes are all of mesenchymal origin. However, while a strong ECM is the principal functional entity of bone and cartilage, the basal lamina of adipose tissue may be more of a necessity for survival of the adipocytes. Mature human adipocytes store triglycerides in a single fat droplet that almost entirely fills the cell volume. Since only a lipid monolayer forms the boundary between stored fat and cytosol, mechanical stress on such an organelle may easily lead to disruption. Transfer of mechanical stress from the outside to the inside of the cell can be decreased 
by the strong external skeleton. In addition, a strong extracellular scaffold can by linking the basal lamina of adipocytes diminish locally experienced mechanical stress by spreading forces over a larger area of the tissue. A specific requirement of the ECM for cell survival indicates that the development of preadipocytes into fat-storing adipocytes should be accompanied by specific changes in the make-up of the ECM.

\section{Adipocyte ECM protein composition}

Since the function of the ECM will depend on, and thus will be reflected by, its molecular make-up, it is important to know which proteins have been identified so far as part of the adipocyte ECM. Overall, the ECM of adipocytes seems composed of the same proteins as found in other cell types. It is more the relative quantity in which those factors are combined that determines the cell-specificity of the ECM. Furthermore, this composition is related to the developmental stage, viability, and subtype of the adipocytes. The two main classes of ECM proteins are proteoglycans (Fig. 1) and fibrous proteins to which most published information is referring.

Early studies on the protein composition of the ECM have used immunological techniques with or without protein labeling. In this way, Aratani and Kitagawa [2] demonstrated the presence of collagen IV, laminin complexes, and nidogen (entactin) in the ECM of mouse 3T3-L1 adipocytes. In differentiated bovine intramuscular preadipocytes (BIP), Nakajima et al. [3] showed the presence of type I-VI collagens, laminin and fibronectin, whereas based on staining, type II collagen was found to have an extremely low abundance. With the emerging of proteomics techniques, several studies of the adipocytes secretome have been performed. From those, an impression can be obtained on the protein composition of the adipocyte ECM. Based on current literature [2-13], a list of core proteins annotated to be part of the adipocyte ECM is shown in Table 1. This leaves out those proteins that are presently described as secreted or membrane proteins, some of which might interact with the ECM. Although there are a number of microarray studies on adipocytes, we have exclusively focused on proteomics data to avoid possible discrepancies between mRNA and protein levels. Altogether, 20 subunits of 12 different types of collagen have been identified from rodent cells, whereas subunits of collagens II, XI, and XXIII were not found with human visceral adipocytes. This might suggest species- or fat depot-specific differences. However, the failure to detect a protein cannot be taken as proof of its absence, because the chance of detection depends on the biochemical characteristics of a protein, on experimental conditions, and on employed proteomics techniques [14].

Compared to other ECM components, collagen VI seems more specific for adipocytes. It is highly enriched in adipocytes, and there is evidence of its contribution to the pathology of obesity-related diseases $[15,16]$. The presence of all three subunits, $\alpha 1(\mathrm{VI}), \alpha 2(\mathrm{VI})$, and $\alpha 3(\mathrm{VI})$, is required for the stable formation of collagen VI [17]. Using the yeast two-hybrid system, collagen VI was shown to be able to strongly bind to collagen IV, an important component of the basement membrane. Both collagens are classified as non-fibrillar types and their interaction has been suggested to mediate anchoring of the basement membrane to cells. Collagen VI has also been shown to
Fig. 1 Visualization of the ECM of 3T3-L1 preadipocyte (a) and adipocytes (b) by immunohistological staining of heparin sulfate proteoglycan: green heparin sulfate proteoglycans stained by antibody (10E4 epitope; Seikagaku, Tokyo, Japan); red nuclear stained with propidium iodide. The fat droplets are visible as dark vesicles in the cytosol
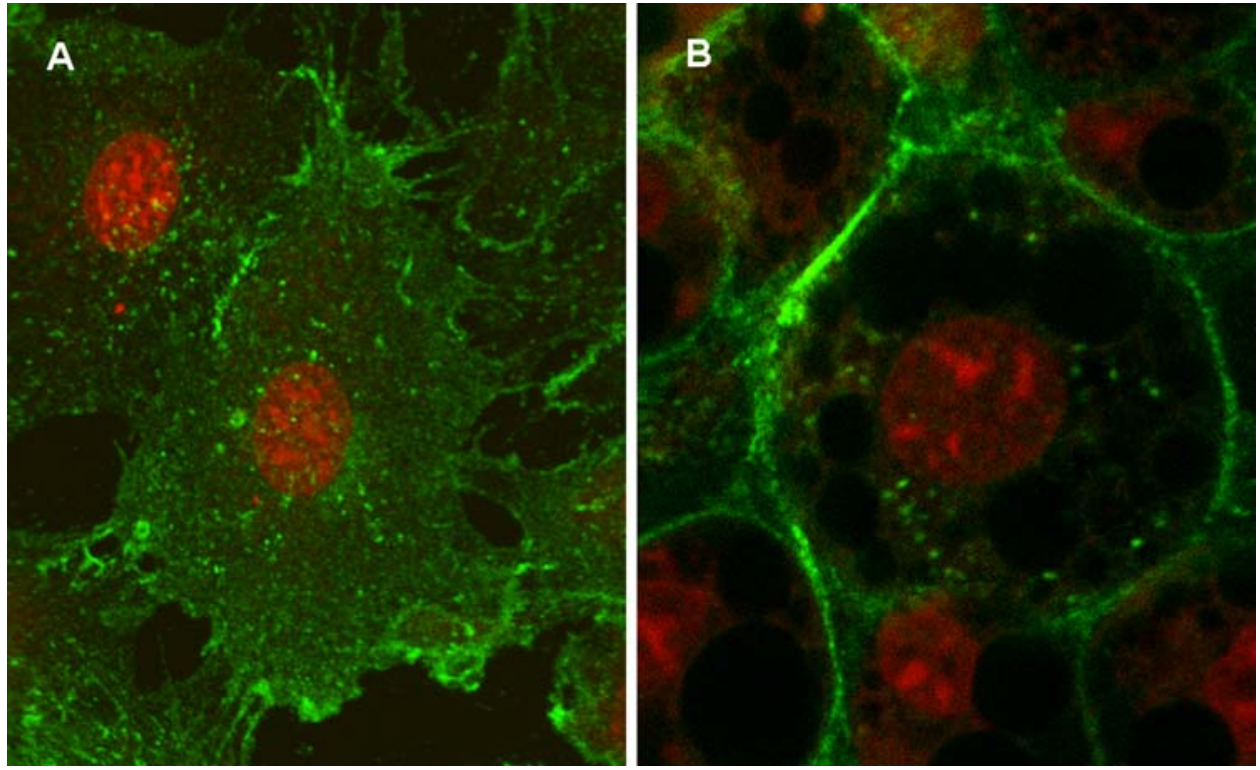


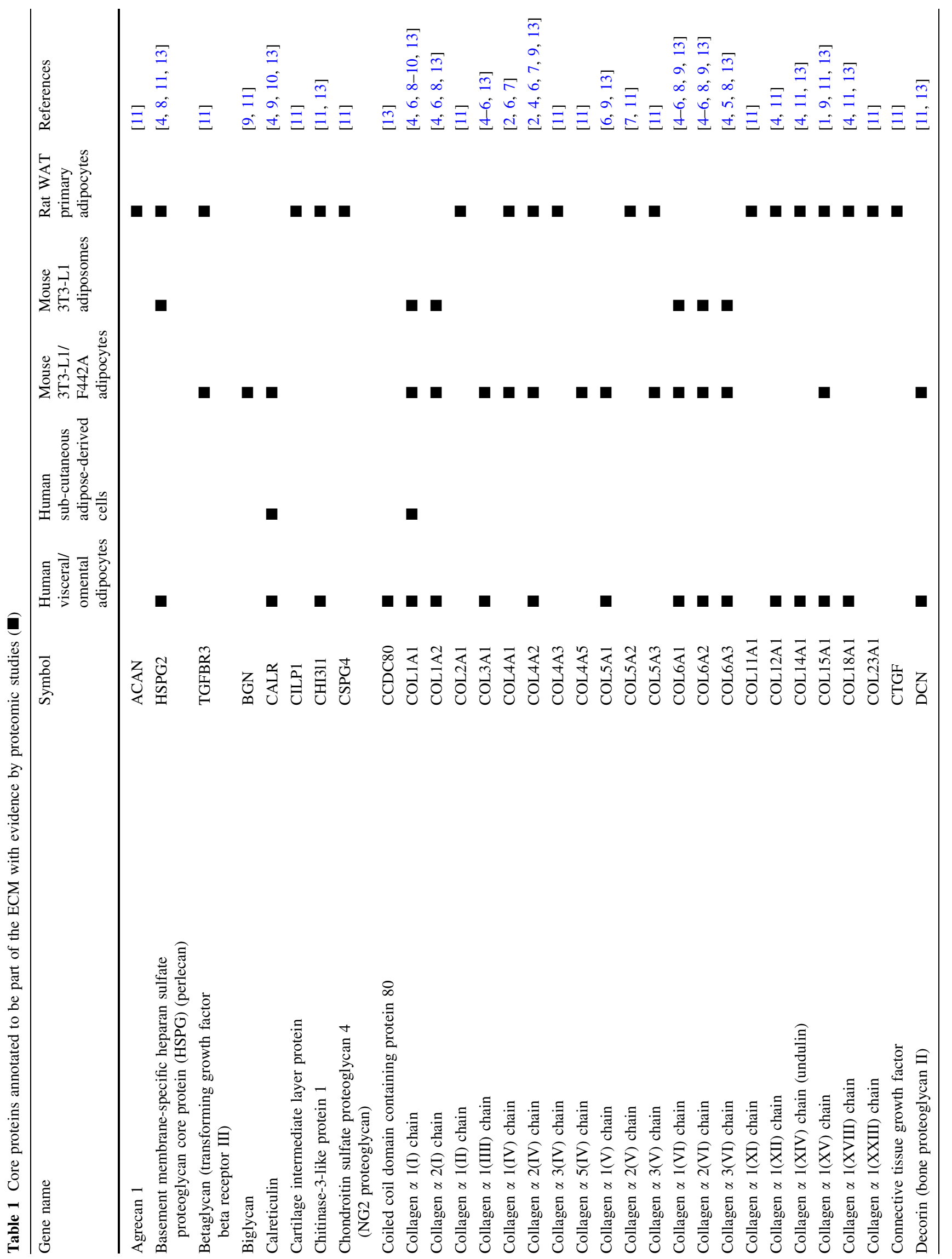




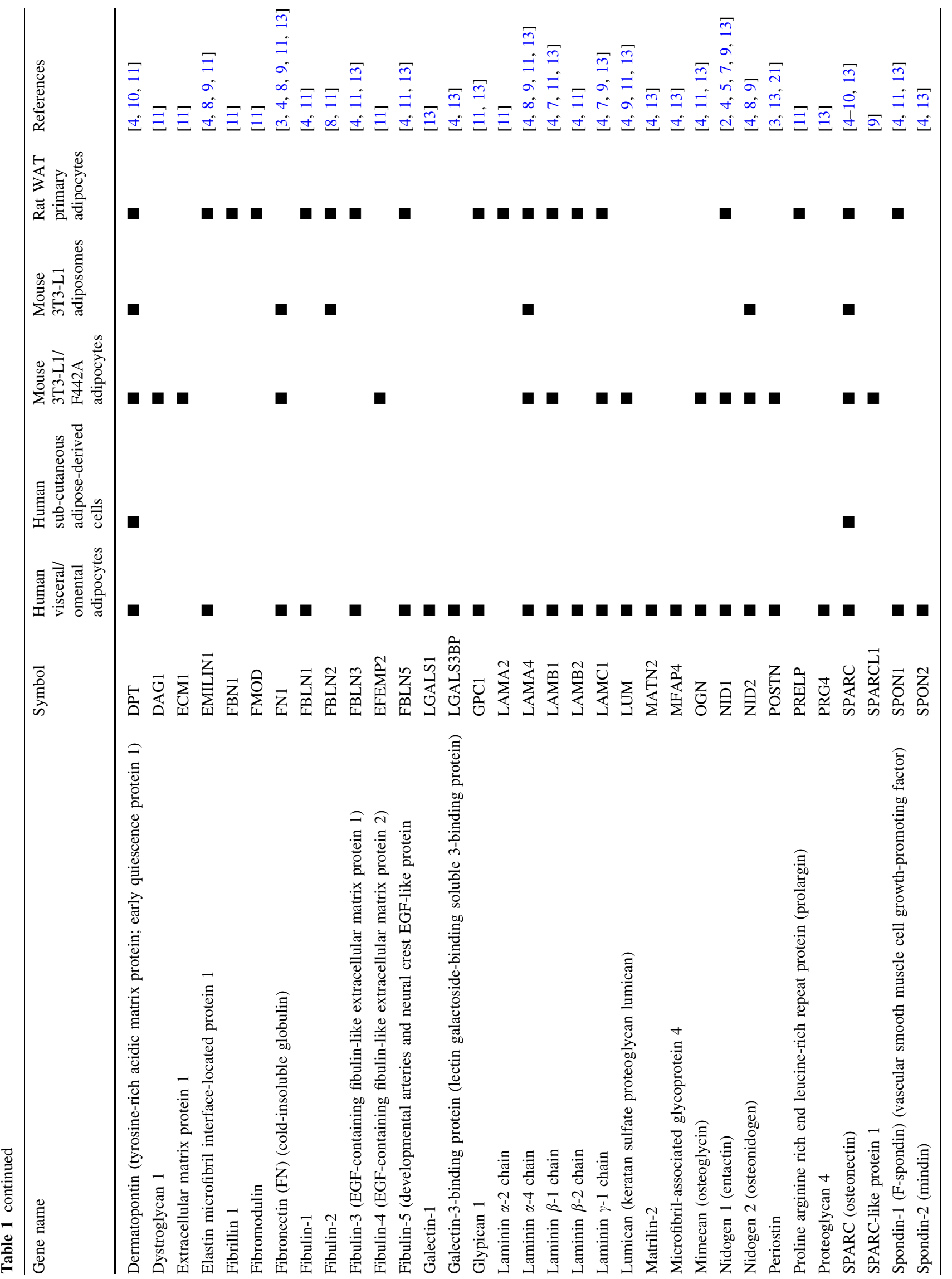




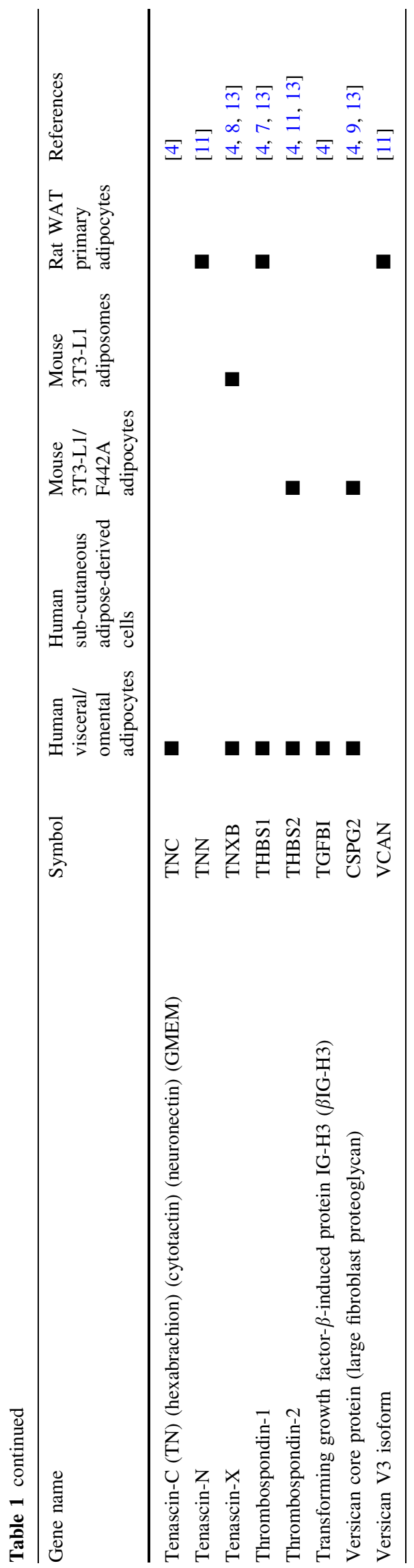

interact with other matrix proteins like proteoglycans and fibronectin. One study reported on the composition of adiposomes from mouse 3T3-L1 cells, the vesicles by which adipocytes are supposed to perform part of their endocrine function with the secretion of adipokines [8]. ECM proteins may become part of those vesicles as contaminants during their transportation or experimental preparation. On the other hand, the presence of collagens may be natural, because procollagens are packed into vesicles and secreted as such into the extracellular space. Remarkably, only collagen types I and VI were detected in adiposomes. It suggests that these collagens are specifically involved in the secretion of adipokines through those vesicles.

\section{Biphasic ECM development during adipogenesis}

The developmental dynamics of the ECM proteins has mainly been studied in vitro using differentiation of mouse 3T3-L1 preadipocytes. Aratani and Kitagawa [2] found a strong up-regulation of collagen IV, nidogen-1 (entactin), and various laminin complexes during the first few days of a 6-day differentiation period indicating the transition from a fibrillar to a laminar make-up.

Studies on the adipocyte secretome during adipogenesis also reveal useful information on the ECM components. Notably, in vitro cell culture medium contains not only intact or detached ECM components but also processing byproducts and degradation products of the ECM. Therefore, the amount of ECM proteins in the secretome may reflect both synthesis and degradation. Our group observed different patterns of expression for the various collagens detected in the medium during a 12-day period of differentiation and growth of 3T3-L1 cells. In the early phase of differentiation, there occurred a decrease of collagens type I and type III, whereas at a later stage, their level returned to that of day 0 . The same pattern was found for the C-terminal processing peptides of those collagens, suggesting that the observed changes related to the synthesis of collagen. In parallel with this decrease of fibrillar collagens, an increased liability of the cells to detach from the culture dish was observed around day 4. An opposite pattern was seen for the components of collagen VI. They initially increased and later declined, but remained at a higher level compared to day 0. Collagen IV, the major collagen of the basal lamina, and collagen $\mathrm{V}$ gradually increased during differentiation.

In the study of Molina et al. [9] with a 7-day differentiation period of 3T3-L1 cells, the vast majority of secreted proteins were seen to be down-regulated at day 1. However, most of the matrix components were around basal level at day 1 and peaked at day 3, including laminins, 
nidogens, biglycan, lumican, SPARC, and EMILIN1. In accordance with our observation, the same peaking behavior was observed for the components of collagen VI. Contrastingly, in this study, collagen IV subunit COL4A2 showed a similar peaking pattern as the other collagens ending at $50 \%$ of their basal level on day 7 .

The variation in the results of the above studies may be ascribed to differences in protein preparation methods and in the ways that the data are quantified. In keeping with the biphasic pattern of collagen synthesis during differentiation of mouse preadipocytes, Nakajima et al. [18] reported the remodeling of collagen $\mathrm{V}$ and $\mathrm{VI}$ matrices using immunohistochemical staining of BIP cells with distinct ECM networks at days 4 and 10 of differentiation. What can be concluded is that, in the first days after the induction of adipogenesis, ECM dynamics reaches one of its highest levels with increasing production of components of the basal lamina. In line with the biphasic production of ECM components, the two phases of adipogenesis seem to be an early phase of commitment and differentiation, and a subsequent phase of cell growth characterized by massive fat storage.

When in 1974 Green and Meuth [19] reported the selection of the 3T3-L1 cell-line from Swiss mouse embryos, they measured proline hydroxylation and from that calculated the extent of collagen synthesis. The high level of collagen synthesis confirmed the fibroblast origin of those cells. During this assay, an interesting comparison was made between 3T3-L1 and another clone, 3T3-M2. The latter did not store fat and at the same time had a $50 \%$ lower rate of proline hydroxylation. This raises the question, whether collagen synthesis is a prerequisite for differentiation and fat storage. Experimental evidence exists in support of such a control mechanism.

Using ethyl-3,4-dihydroxybenzoate (EDHB) as a specific inhibitor of collagen synthesis, it has been shown that, in TA1 cells, preadipocytes derived from mouse 10T1/2 embryonic cells, differentiation and triglyceride accumulation were blocked in a dose-dependent manner [20]. This effect was only obtained when EDHB was added to preadipocytes but not when added to already differentiating cells. This suggests that collagen synthesis may serve different purposes during the early and late stages of adipocytes development. Early collagen synthesis seems a permissive requirement for the onset of differentiation, whereas late collagen synthesis may be more related to specific functions of the adipocytes and the adipose tissue, such as providing stability to the fat-storing cells. Such a requirement of collagen synthesis for cell differentiation may well be a general phenomenon and is not confined to preadipocytes [21].

Also in BIP cells, both collagen synthesis and triglyceride accumulation could be inhibited in a dose-dependent manner by EDHB [22]. However, a stage-dependency was not observed. Looking in detail at collagens I-VI, the synthesis of all collagens except type III collagen was significantly affected with the most dramatic effects on collagens IV-VI. Interestingly, based on measurements of triglyceride accumulation, the inhibitory effect of EDHB on BIP cells could be reversed to a significant extent by culturing EDHB-treated cells in wells coated with collagen V or VI. This indicates that particularly the synthesis of collagens $\mathrm{V}$ and VI is important for the collagen-dependent initiation of preadipocyte differentiation and triglyceride storage.

\section{Adipocyte ECM maintenance}

The importance of the ECM for the function and survival of the adipocytes was demonstrated when we investigated protein-dynamics in mature non-dividing 3T3-L1 adipocytes by stable isotope protein labeling [23]. Among the limited number of examined proteins in this study there were three ECM components, COL1A1, COL1A2, and calreticulin. Both collagens showed the highest rate of labelling among all investigated proteins. Moreover, the calculated isomer-exchange rate for COL1A1 and COL1A2 was $2: 1$, exactly the ratio by which they constitute the triplex collagen type I fibers indicating that the synthesis of the collagen I subunits is coordinated. Lower, but still considerable, labeling was seen for calreticulin and for the ECM processing enzyme protein disulfide isomerase (PDIA1 and PDIA3). What can be learned from this is that there is a constant turnover of the adipocyte ECM even in mature cells. Apparently adipocytes spend a lot of attention and, likely, a lot of metabolic energy on the maintenance of their ECM. It should be kept in mind, however, that the high collagen synthesis may be an effect of two-dimensional cell culture and may not accurately reflect the in vivo situation.

\section{ECM-dynamics: a role for ECM-protein processing enzymes}

The relatively high degree of collagen replacement in mature adipocytes suggests that the ECM is under constant turnover, which is mediated by enzymes promoting construction of the ECM and enzymes involved in its degradation. Accordingly, for mature adipocytes, there has to be a balance between those processes, whereas during preadipocyte differentiation this balance is shifted towards the constructive factors. In Table 2, processing enzymes are listed that have been detected at the protein level. The constructive enzymes fall into two classes, the intracellular enzymes involved in processing of precursors of ECM- 
Table 2 ECM-protein processing enzymes

\begin{tabular}{|c|c|c|c|c|}
\hline Gene name & Symbol & $\begin{array}{l}\text { UniProtKB } \\
\text { accession }\end{array}$ & Location & Reference \\
\hline $\begin{array}{l}\text { A desintegrin and metalloproteinase with } \\
\text { thrombospondin type 1motif, } 1\end{array}$ & ADAMTS1 & Q9UHI8 & Sec, ECM & [11] \\
\hline A desintegrin and metalloproteinase with thrombospondin motifs 4 & ADAMTS4 & $\mathrm{O} 75173$ & Sec, ECM & [4] \\
\hline A desintegrin and metalloproteinase with thrombospondin motifs 5 & ADAMTS5 & Q9UNA0 & Sec, ECM & [11] \\
\hline Colligin (collagen-binding protein) & SERPINH1 & P50454 & ER & {$[5]$} \\
\hline Contrapsin-like protease inhibitor 6 & serpina3n & P09006 & $\mathrm{Sec}$ & [7] \\
\hline Matrix metalloproteinase-1 & MMP1 & P03956 & Sec, ECM & {$[4,13]$} \\
\hline Matrix metalloproteinase-2 & MMP2 & P08253 & Sec, ECM & {$[4-9,13]$} \\
\hline Matrix metalloproteinase-9 & MMP9 & P14780 & Sec, ECM & {$[4,7,8]$} \\
\hline Matrix metalloproteinase-10 & MMP10 & P09238 & Sec, ECM & [13] \\
\hline $\begin{array}{l}\text { Matrix metalloproteinase } 14 \text {; membrane-type-1 matrix } \\
\text { metalloproteinase }\end{array}$ & MMP14; MT1-MMP & P50281 & ECM, cell membrane & {$[37,38]$} \\
\hline Matrix metalloproteinase-19 & MMP19 & Q99542 & Sec, ECM & [11] \\
\hline Metalloproteinase inhibitor 1 & TIMP1 & P01033 & Sec, ECM & {$[4,7,13]$} \\
\hline Metalloproteinase inhibitor 2 & TIMP2 & P16035 & $\mathrm{Sec}$ & {$[6,11,13]$} \\
\hline Peptidyl-prolyl cis-trans isomerase A (cyclophilin A) & PPIA & P62937 & Cyt & {$[6,9]$} \\
\hline Peptidyl-prolyl cis-trans isomerase B (cyclophilin B) & PPIB & P23284 & ER & {$[4,9,11,13]$} \\
\hline Peptidyl-prolyl cis-trans isomerase (FK506-binding protein 9) & FKBP9 & O95302 & ER & {$[9,12]$} \\
\hline Plasminogen activator inhibitor 1 & SERPINE1 & P05121 & $\mathrm{Sec}$ & {$[4,7,10,13]$} \\
\hline Procollagen C-proteinase (bone morphogenic protein 1) & BMP1 & P13497 & $\mathrm{Sec}$ & [11] \\
\hline Procollagen C-proteinase enhancer protein & PCOLCE & Q15113 & $\mathrm{Sec}$ & {$[4,6,11,13]$} \\
\hline Procollagen-lysine,2-oxoglutarate 5-dioxygenase 1 & PLOD1 & Q02809 & ER, cell membrane & {$[9,11]$} \\
\hline Procollagen-lysine,2-oxoglutarate 5-dioxygenase 2 & PLOD2 & O00469 & ER, cell membrane & [11] \\
\hline Procollagen-lysine,2-oxoglutarate 5-dioxygenase 3 & PLOD3 & O60568 & ER, cell membrane & {$[4,11]$} \\
\hline Prolyl 4-hydroxylase, alpha subunit & P4HA1 & P13674 & ER & {$[10,12]$} \\
\hline Protein-disulfide isomerase & P4HB & P07237 & ER, cell membrane & {$[4,10]$} \\
\hline Protein-disulfide isomerase A3 & PDIA3 & P30101 & ER & {$[4,10,13]$} \\
\hline Protein-disulfide isomerase A4 & PDIA4 & P13667 & ER & [9] \\
\hline Protein-disulfide isomerase A6 & PDIA6 & Q15084 & ER & {$[4,9,13]$} \\
\hline Protein-lysine 6-oxidase & LOX & $\mathrm{P} 28300$ & $\mathrm{Sec}$ & {$[6,11]$} \\
\hline Lysyl-oxidase homologue 1 & LOXL1 & Q08397 & $\mathrm{Sec}$ & [11] \\
\hline Transforming growth factor beta induced protein ig-h3 & TGFBI & Q15582 & Sec, ECM & [11] \\
\hline Visceral adipose tissue-derived serine protease inhibitor (vaspin) & SERPINA12 & Q8IW75 & $\mathrm{Sec}$ & [35] \\
\hline
\end{tabular}

Sec Secreted, ECM extracellular matrix, ER endoplasmic reticulum, $C y t$ cytosol

proteins and the extracellular inhibitors of the degrading enzymes. The degrading enzymes by themselves belong to either of two systems [24], the fibrinolytic system and the matrix metalloproteinases (MMPs). Although adipocytes express these enzymes, the contribution from the stromal vascular fraction can be significant [25].

The intracellular maturation of newly synthesized ECM-proteins takes place in the ER. There, the proteins undergo biochemical modification of amino acid sidechains. The ECM proteins then undergo processing by proteolytic cleavage before they are assembled into the ECM network. For collagen subunits, this can involve proline- and lysine-hydroxylation and glycosylation and removal of the $\mathrm{N}$ - and $\mathrm{C}$-terminal peptides by procollagen-N- and -C-collagenase, respectively. After processing, proteins are self-assembled into monomers depending on the type of collagens and are then secreted. Experiments have shown how crucial can be the role of intracellular processing enzymes. Ibrahim et al. [20] demonstrated the inhibitory effect of EDHB on collagen protein synthesis, but at the same time reported that early administration of EDHB did not influence the mRNA level of collagen 6A2. Further, Nakajima et al. [22] showed that EDHB inhibits the assembly of subunits into collagen molecules, 
which is in keeping with EDHB influencing a post-transcriptional process of collagen formation. EDHB is a structural analog of ascorbate and $\alpha$-ketoglutarate (2-oxoglutarate), which are both essential cofactors of the enzyme prolyl hydroxylase (P4HA1). Apparently, this enzyme activity is crucial for collagen formation and preadipocytes differentiation. Notably, EDHB is not specific for this particular enzyme but is an inhibitor for the whole family of prolyl hydroxylases [26].

Extracellular procollagen processing involves the cleaving-off of both $\mathrm{N}$-terminal and C-terminal peptides [27]. Procollagen I/II amino propeptide-processing enzyme (ADAMTS-2) cleaves the N-terminal propeptide from the subunits of collagens I and II: COL1A1, COL1A2, and COL2A1. Cleavage takes place after assembly of two 1A1and one 1A2-chains into a collagen type I monomer before those monomers multimerize into fibrils. The process requires the native conformation of the procollagens in which the N-terminus can adopt a hairpin structure. During the reaction, an intermediate is formed that has lost the $\mathrm{N}$-propeptide from one 1A1-chain and from the 1A2-chain, but still contains the propeptide on the other 1A1-chain. Conformational changes in the $\mathrm{N}$-terminus are suspected to be involved in determining this defined sequential cleavage of the propeptides [28]. Mutations in ADAMTS-2 can give rise to Ehlers-Danlos syndrome type VIIC in humans, a defect of the cartilage. Procollagen amino propeptide-processing activity has also been observed for gene family members of ADAMTS-2. ADAMTS-3 can process procollagen II but not procollagen I. Both N-proteinases lack the activity to process collagen III. Collagen I processing activity has also been observed for ADAMTS-14.

Collagen fibril formation also requires that the C-terminal peptides are removed from the subunits by proteolytic cleavage [27]. For collagens I-III this is done by the enzyme procollagen-C-proteinase, also referred to as mammalian tolloid protein or bone morphogenic protein 1 (BMP1). In contrast to ADAMTS-2, native collagen conformation is not a prerequisite for processing of the C-terminus. In addition to collagens, this enzyme processes the precursors of laminin 5 and biglycan, and of the modifying enzyme lysyl oxidase (LOX). Via alternative splicing, different isoforms of the C-proteinase can be formed [27].

Plasmin is the active component of the fibrinolytic system. It is able to cleave not only fibrin and von Willibrand factor but also some adipocyte ECM components: fibronectin, thrombospondin, and laminin. The activity of plasmin is regulated by several other proteins including the urokinase-type (u-PA) and the tissue-type (t-PA) plasminogen activators and plasminogen activator inhibitors (PAIs) (Fig. 2). The effect of the fibrinolytic system on adipose tissue has been studied in the mouse by abolishing or over-

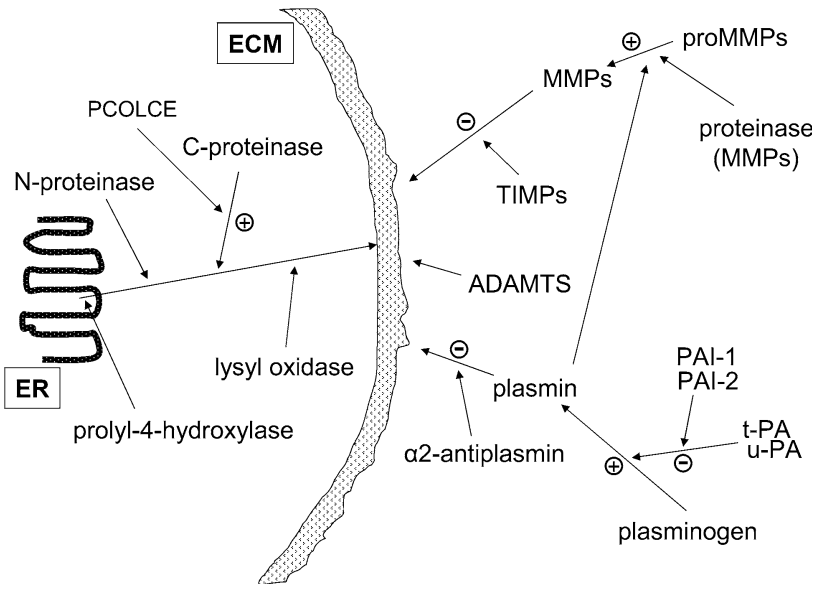

Fig. 2 Overview of some of the proteins involved in regulating the maintenance and turnover of the adipocyte ECM

expressing one of those genes, but it is difficult to fit all observations into a uniform effect-model ([24] and references therein). The various findings suggest that this system affects angiogenesis rather than directly influencing ECM remodeling and adipogenesis. Sufficient blood flow by angiogenesis favors adipose tissue formation. Nevertheless, PAI-1 seems able to prevent the degradation of the ECM. Pharmacological inhibition of PAI-1 in different studies with mice on a high fat diet leads to reduced body weight, weight of fat depots, and adipocyte volume [29, 30]. Here, a higher blood vessel density in adipose tissue was observed, but this may be the consequence of the reduced volume of the fat pads.

More than 20 different members of the MMP family have been identified. Although MMPs collectively degrade ECM proteins, according to the UniProt database there is some form of substrate specificity (Table 3). Changing MMP expression in the mouse can influence adiposity. Inactivation of MMP3 on a high-fat diet results in increased development of adipose tissue with a hyperplastic as well as a hypertrophic response [31]. Similar observations were made after inactivation of MMP9 and MMP11 [24, 32]. Contrasting observations have been made with pharmacological inhibition of MMPs in mice on a high-fat diet. Co-inhibition of MMPs 2, 9, and 14 did not influence adipose tissue development [33], whereas the general inhibition of MMP activity led to a reduction in adipose tissue weight [34]. These sometimes controversial results reflect the complexity of MMP activity that depends on relative concentrations of different MMPs, their substrate specificity, and the activity of their inhibitors, the tissue inhibitors of metalloproteinases (TIMPs), and perhaps several others [24, 35].

No information can be obtained from the Uniprot database about an MMP that has collagen VI as a substrate, but recent investigations have provided information on this. 


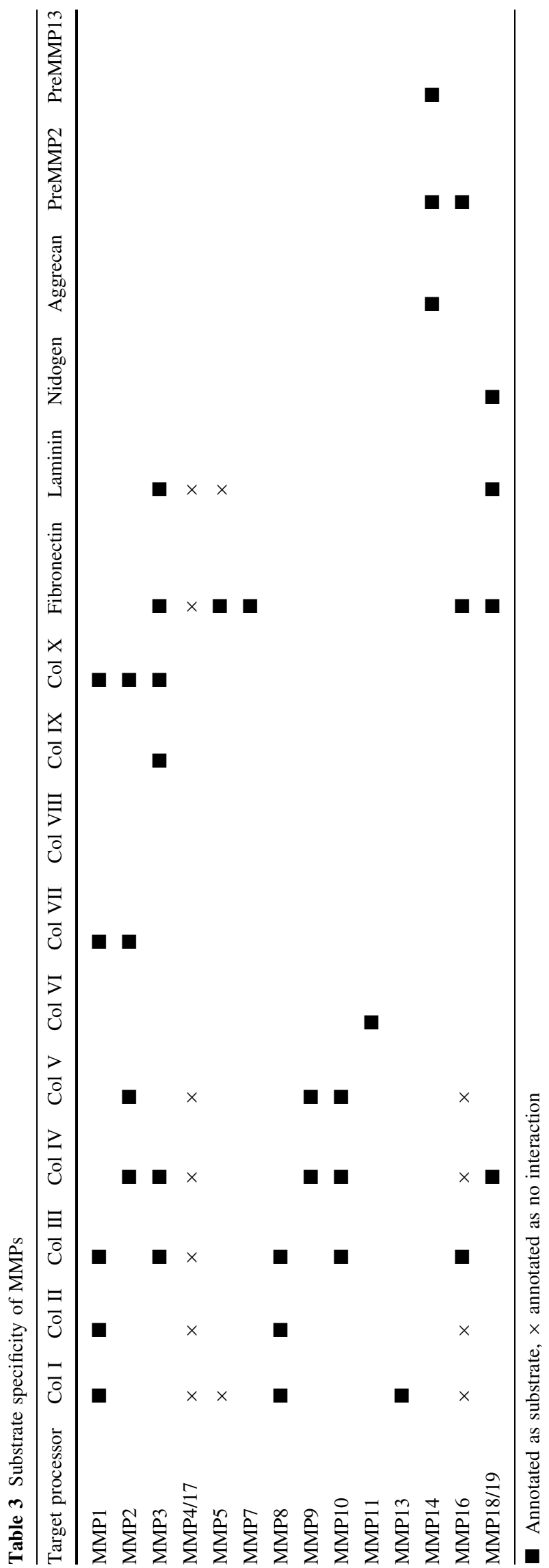

Studies on breast cancer have indicated that adipocytes may support cancer cells. In this context, a role for collagen VI has been put forward [15]. Also, it was observed that MMP11 is associated with tumor invasion and poor prognosis. Further studies showed that COL6A3 is a substrate of MMP11 [36]. Moreover, MMP11 appears to be a strong negative regulator of adipogenesis [37] in line with the above-mentioned observations in MMP11 deficient mice.

All MMPs are secreted as inactive zymogens and need proteolytic cleavage to become activated by other MMPs or plasmin. The MMP most often reported in proteomics studies is MMP2 cleaving the basal lamina component collagen IV (Table 3). MMP2, as well as MMP13 (collagenase 3), is activated by MMP14 (MT1-MMP). Chun et al. [38] observed that adipocytes from MT1-MMP null-mice were $10 \times-$ smaller in diameter than wild-type adipocytes. Knock-out preadipocytes were able to differentiate on planar interfaces but, when cultured in a 3D matrix of collagen I fibrils, they failed to differentiate and did not accumulate triglycerides. The conclusion was that MT1-MMP is necessary for the modulation of rigid pericellular collagen to allow preadipocytes to grow out of the stroma. Observations on vascular smooth muscle cells indicate that MT1-MMP activity is also able to directly remodel the matrix by itself [39].

Four TIMPs (Table 4) have been detected up to now [40]. Like their counter players, the MMPs, TIMPs are regulated during adipogenesis [41]. In relation to adipose tissue development, TIMP1 has been studied the most [42]. A recent report suggests that, beyond direct adipose tissue ECM remodeling, TIMP1 may have an effect on adipose tissue development by acting in the hypothalamus to regulate food intake [43]. Interestingly, TIMP4 is specifically expressed in adipose tissue and adipocytes in humans according to tissue-wide gene expression analysis of UniGene [44] and GNF Gene Atlas [45], and is highly regulated [46]. However, little is known about its function for ECM remodeling and adipose tissue development. Overall, it seems that the balance between TIMPs and MMPs, or their ratio, is more relevant than the activity of the individual groups of those processing enzymes.

A subfamily of metalloproteinases is the A Desintegrin And Metalloproteinase with Trombospondin motif (ADAMTS family). Members of this family have been found to have procollagen $\mathrm{N}$-proteinase activity as mentioned above, but other members also may influence adipose tissue development. In the mouse, expression of ADAMTS-1, $-4,-5$, and -8 has been demonstrated in adipose tissue, and their expression level changes during the development of diet induced obesity. Expression seems highest in the stromal vascular fraction, which is in line with a suggested role in early steps of preadipocyte differentiation by the 
Table 4 MMPs and their inhibitors

\begin{tabular}{|c|c|c|c|c|}
\hline Inhibitor target & TIMP1 & TIMP2 & TIMP3 & TIMP4 \\
\hline MMP1 & $\mathbf{\square}$ & $\mathbf{\square}$ & $\square$ & $\square$ \\
\hline MMP2 & $\mathbf{\square}$ & $\mathbf{\square}$ & $\mathbf{\square}$ & $\mathbf{\square}$ \\
\hline MMP3 & $\mathbf{\square}$ & $\mathbf{\square}$ & $\mathbf{\square}$ & $\mathbf{\square}$ \\
\hline MMP4 (MMP17) & & & & \\
\hline MMP5 (MMP24) & & & & \\
\hline MMP6 (MMP25) & & & & \\
\hline MMP7 & $\mathbf{\square}$ & $\square$ & $\square$ & $\square$ \\
\hline MMP8 & $\mathbf{\square}$ & $\square$ & & \\
\hline MMP9 & $\mathbf{\square}$ & $\mathbf{\square}$ & $\mathbf{\square}$ & $\mathbf{a}$ \\
\hline MMP10 & $\mathbf{\square}$ & $\mathbf{\square}$ & & \\
\hline MMP11 & $\mathbf{\square}$ & $\mathbf{\square}$ & & \\
\hline MMP12 & $\mathbf{\square}$ & $\mathbf{\square}$ & & \\
\hline MMP13 & $\mathbf{\square}$ & $\mathbf{\square}$ & $\mathbf{\square}$ & \\
\hline MMP14 & $x$ & $\mathbf{\square}$ & $\mathbf{\square}$ & \\
\hline MMP15 & & $\mathbf{\square}$ & $\mathbf{\square}$ & \\
\hline MMP16 & $\mathbf{\square}$ & $\mathbf{\square}$ & & \\
\hline MMP18 & & & & \\
\hline MMP19 & & $\square$ & & \\
\hline MMP20 & & & & \\
\hline MMP21 & & & & \\
\hline MMP22 (MMP23) & & & & \\
\hline
\end{tabular}

Annotated as substrate, $\times$ annotated as no interaction

degradation of aggrecan, a chondroitin sulphate/keratan sulphate proteoglycan [47].

\section{Regulation of ECM dynamics}

\section{ECM regulation and insulin}

Some years ago, we studied the influence of insulin on the secretome of mature 3T3-L1 adipocytes [48]. Insulin induced a clear increase of the mature form of COL1A1, of a COL5A1 fragment, and of the C-terminal peptides of COL1A1, COL1A2, and COL3A1. A comparison with transcriptomics data showed that insulin did not up-regulate transcription of those genes. It was concluded that insulin acts at the level of post-transcriptional processing and secretion. In keeping with this, was the observed increase in relative abundance of PCOLCE, procollagen $\mathrm{C}$-endopeptidase enhancer protein, that can activate the C-endopeptidase by 20 -fold. Remarkably, we observed a significant up-regulation of the mRNA levels for various matrix protein processing enzymes including sulfatase 2 and prolyl hydroxylase, and a trend for increase of the mRNA for PCOLCE. Altogether, our data indicate that insulin up-regulates the transcription of genes for protein- modifying and -processing enzymes and in that way stimulates the formation of ECM-components and the ECM as a whole. This activity seems not confined to the ECM components, as a considerable increase of other secreted proteins was also observed without concomitant increase of their mRNA levels including adipsin and complement C3 [48]. In general, the observed effects of adding insulin to the cell culture medium were even stronger when the experiments were done in the presence of extra glucose. The experiments leading to the above effect of insulin activity mimic an acute increase in insulin on mature adipocytes. For preadipocytes in vitro, insulin is a potent stimulator of differentiation and triglyceride storage in line with its general anabolic role.

The detection of up-regulated expression of the gene for sulfatase 2 indicates that insulin changes the level of 6-Osulfation of heparan sulfate proteoglycans (HSPGs) [48]. Wilsie et al. [49] detected a clear influence of HSPGs on lipid uptake in 3T3-L1 adipocytes. They propose a model in which HSPG serves as a binding site for lipid particles (apoE-VLDL). As such, a reaction center is created for the rapid hydrolysis of triglycerides from the particles by lipoprotein lipase and for the delivery of the fatty acids to the membrane bound fatty acid transporters. Alternatively, lipid particles are internalized together with HSPGs at which they have accumulated. In this way, the ECM plays a crucial role in lipid uptake which is in some way regulated by insulin.

\section{ECM regulation and energy metabolism}

When preadipocytes differentiate and cells begin to store fat, their ECM adopts a basal laminar structure. Uptake and storage of fatty acids depends on gene regulation through the activity of the nuclear receptor PPAR $\gamma$ in combination with another nuclear receptor, RXR. The parallel fat-storage and ECM development suggests that both processes might be concertedly regulated by PPAR $\gamma$. However, not many genes for ECM components or their processing enzymes have been shown to be direct targets of PPAR $\gamma$. Suggestive results have been obtained for COL6A3 and thrombospondin 1 [50]. A specific responsive element for binding PPAR $\gamma$ exists in the promoter of the rodent gene for MMP1 [51]. When rosiglitazone, a strong agonist of PPAR $\gamma$, was added to mature 3T3-L1 adipocytes, the cells lost $10 \%$ of their triglycerides. At the same time, a down-regulation was observed of the expression of genes for matrix proteins and various processing enzymes [52]. This suggests that reduction of the net triglyceride content of the cell maybe accompanied by reduction of the cell volume, while the building-up of the ECM is slowed down via transcriptional down-regulation. However, this effect seems not confined to ECM-proteins but also applies to other secreted proteins. 
Fig. 3 Summary of the factors that influence the activity of the prolyl hydroxylase/protein disulfide isomerase (PH/PDI) enzyme complex

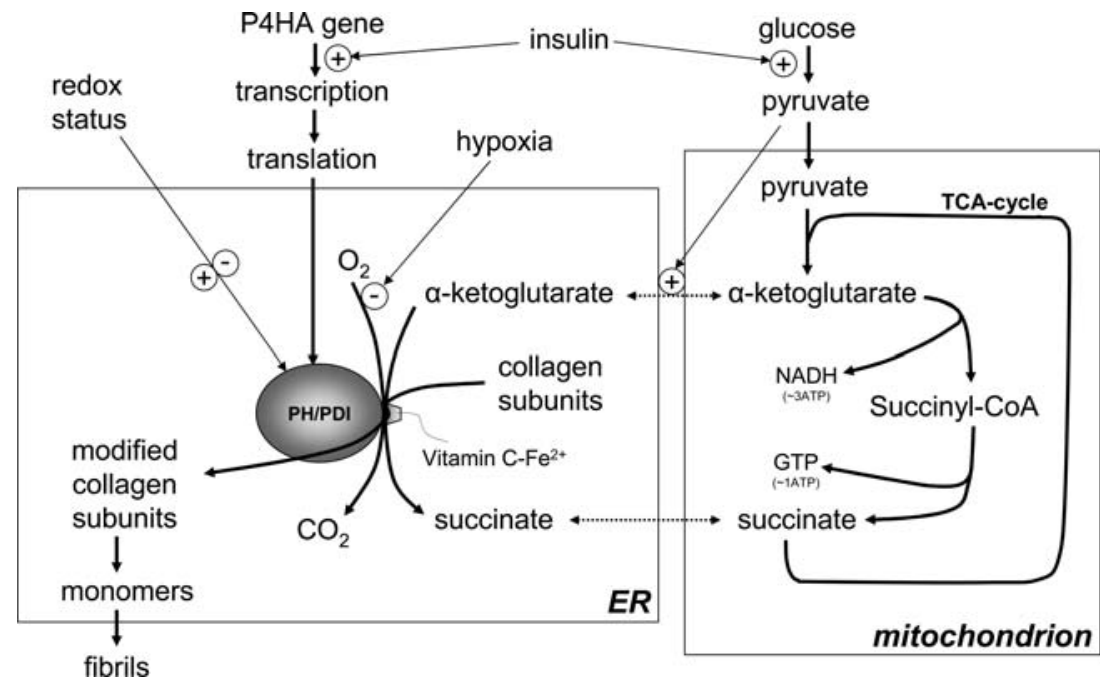

As mentioned above, an important way to control the turnover of the ECM in mature adipocytes is by regulating the processing enzymes for the synthesis and the breakdown of ECM proteins. An interesting protein complex in this respect is the enzyme prolyl-4-hydroxylase, which is involved in the modification of collagens necessary for their assembly into collagen monomers and fibrils. It is a tetramer of two alpha-1 chains (P4HA1) and two beta subunits, also referred to as protein disulfide isomerase (P4HB, PDI). The location of this complex is most likely the ER where the alpha-chains of the enzyme complex convert proline residues in collagens to 4-hydroxyproline. It requires vitamin $\mathrm{C}$ (ascorbic acid) as a cofactor supplying $\mathrm{Fe}^{2+}$ for the reaction. In addition, the reaction requires $\mathrm{O}_{2}$ and $\alpha$-ketoglutarate and converts them to $\mathrm{CO}_{2}$ and succinate, respectively. In principle, this conversion might be regarded as a shunt in the TCA cycle (Fig. 3) revealing that one proline hydroxylation costs an energy equivalent of four ATPs (one GTP and one NADH). Apparently, collagen synthesis is a considerably energy-costing process. In fact, an exchange of metabolites between mitochondrion and ER as in the presumed shunt is not unlikely. For rat pancreatic islet mitochondria, it was shown that $\alpha$-ketoglutarate is a metabolite of the cataplerosis [53]. Moreover, the mitochondria and ER can establish a direct interaction mediated by specific contactproteins [54]. It was observed that pyruvate enhances the secretion of $\alpha$-ketoglutarate from the mitochondria by fourfold [53]. In this respect, collagen synthesis might be influenced by the pyruvate concentration serving as a substrate for $\alpha$-ketoglutarate synthesis and promoting its secretion from the mitochondria. Also, the efficacy of the reaction, and thereby of ECM and adipocyte development, seems to depend on the oxygen supply to the tissue. It is tempting to speculate that this enzyme complex is a site for oxygen sensing as has been shown for other members of the gene family, HIF-prolyl hydroxylase [55, 56]. Various regulatory aspects of the collagen proline hydroxylation are summarized in Fig. 3.

Protein disulfide isomerase (PDI), the molecular partner of prolyl hydroxylase, functions by creating and rearranging disulfide bonds during protein folding in the ER. In line with its catalytic properties, the activity of PDI seems to depend on the redox status in the cell $[57,58]$. The folding of collagens into the proper structure needed for cleavage of the N-terminal peptide is probably just one of the numerous sites of action of this enzyme during formation of ECM components. Not only structural ECM components but also modifying enzymes like TIMP1 and TIMP2 rely for their activity on disulfide bonds. Through enzymes like PDI, the redox status of the cell and in particular the $\mathrm{NADH} / \mathrm{NAD}^{+}$ratio may have a strong influence on the turnover of the adipocyte ECM.

\section{ECM regulation and mechanical forces}

Although one of the functions of the ECM of adipocytes is the protection of the cell against disruption by mechanical forces, this aspect has not been much studied. When 3T3-L1 pre-adipocytes are subjected to mechanical stretching, this results in the inhibition of differentiation. A down-regulation of the expression of the PPAR $\gamma 2$ gene is observed, most likely mediated by the MAPK/ERK pathway [59]. It suggests that, when external forces are sensed, cells may spend their energy more on ECM remodeling, promoting survival than on triglyceride storage. Stretching may also prevent the required change in morphology during differentiation. A relation between cell shape and the potential to differentiate was already demonstrated in 1983 by Spiegelman and Ginty [60]. Allowing 3T3-F442A cells to spread on a fibronectincoated surface inhibited differentiation, whereas this 
effect was not seen when cells were allowed to maintain a spherical shape.

An interesting observation showing the involvement of the ECM in cell morphology development was made in MT1-MMP (MMP14) null mice [38]. Those mice are lipodystrophic, and their pre-adipocytes in an in vitro 3D-culture system adopt a different cell shape as cells from wild-type mice. A down-regulation of CREB and phosphorylated CREB was noticed. It seems as if the cells have lost their capacity to interact with surrounding collagen fibers and thereby lost the traction forces necessary to change shape. In summary, external mechanical forces on the cell influence its power to differentiate and function properly, whereas traction forces from the cell to the surroundings are necessary for cell morphology development. The ECM is an intermediate in both processes.

\section{Other regulators of ECM}

Besides insulin, other hormones, including leptin [61], angiotensin II [62], and estrogen [63], have been addressed to the development of the ECM in other organs but not in adipose tissue. Since adipose tissue expresses these hormones and also their receptors, it can be expected that the adipose ECM may also be under the regulation of these hormones, possibly via autocrine and paracrine action. While leptin and angiotensin II stimulate ECM production via TGF- $\beta$, estrogen protects ECM by reducing MMPs and increasing TIMPs.

The sympathetic nervous system can also be involved in the regulation of ECM dynamics. The study of vascular smooth muscle shows that stimulating $\alpha 1$ - and $\beta 1 / \beta 2$ adrenergic receptors induce and inhibit ECM production, respectively, via TGF- $\beta$ [64]. Although it has not yet been addressed directly in adipose tissue, similar mechanisms may operate through its $\alpha 2$ - and $\beta$-receptors that play a major role in the control of lipolysis.

\section{Adipocyte ECM, weight regulation and obesity}

One of the main functions of adipose tissue is the temporary storage of fat as triglycerides. In case of a positive energy balance, preadipocytes develop into adipocytes, during which cell shape dramatically alters. This process depends on changes in the ECM. As outlined in the previous paragraphs, adipogenesis can be divided in roughly two phases: a first phase in which the cells are committed to triglyceride storage, and a second phase that relates more to the vast increase in the amount of triglycerides accompanied by rounding and growing of the cells.

If mature adipocytes take up more fat, the cell volume increases and so should the ECM [65]. In obese subjects, many of the adipocytes are hypertrophic and the question arises if and how the ECM can cope with this. It is tempting to propose that there is a physical limit to adipocyte growth and that this limit is determined by the ability of the cell to keep the ECM in such a condition that it can protect the cell against disruption. An emerging view is that hypertrophy of adipocytes prevents proper oxygen supply to the cell contents creating a state of hypoxia [66]. Lack of sufficient oxygen will induce apoptosis of some of the cells, which then attracts macrophages and generates a state of inflammation in the tissue that may be part of the pathogenesis of obesity-related disorders like type II diabetes. Not much is known about the mechanistic consequences of hypoxia, but the ECM may be involved. Hypoxia will undoubtedly induce a change in cellular redox status and, as mentioned above, this will lead to malfunctioning of ECM-protein processing enzymes like lysyl oxidase and prolyl-4-hydroxylase, the crucial enzyme for collagen synthesis. In obese insulin-resistant persons, proline hydroxylation may be inhibited even more because of a decreased supply of pyruvate as input for the TCA cycle. Under those conditions, one might expect a destabilization of the ECM with dramatic consequences for the ever-growing adipocytes. As such, the ECM may be an important player in the etiology of type II diabetes. Culturing immortalized or primary rodent adipocytes under high glucose/high insulin concentration or inducing insulin resistance in those cells by the addition of PUGNAc [67] leads to altered composition of the ECM with changes in the relative abundance of several ECM proteins (laminin $\beta-1$ chain, spondin 1, fibulin 2) and matrix processing enzymes (peptidyl-prolyl cis-trans isomerase B, MMP2, TIMP2) [11]. Khan et al. [16] also reported that the metabolic dysregulation of the body in the diabetic state is linked to changes of the adipocyte ECM. Allowing their stress-free expansion by knocking-out collagen VI improved whole body energy homeostasis.

Not much is known about the dynamics of the ECM during a negative energy balance. Yet this is important since, for the obese, the loss of fat mass is a preferred way to lower the risk for complications. When 3T3-L1 adipocytes are starved, they readily lose about $46 \%$ of their fat, but then this process comes to a stop, which can only be overcome by additional measures. Supplementation of the culture medium with $\mathrm{TNF} \alpha$ leads to a further reduction of the fat content to $77 \%$ [68]. One could speculate that the loss of triglycerides decreases the volume of the cell creating stress between the cell contents and the surrounding ECM. This would require the ECM to remodel. However, shrinkage of the ECM may be hard or even impossible. In either case, stress will build up between cell and ECM, and this may inhibit lipolysis explaining why fat loss from adipocytes cannot reach completion. Indeed, $10 \%$ fat loss by rosiglitazone treatment was paralleled by transcriptional 
down-regulation of synthesis and processing of ECM proteins [52].

Inflammation is linked to obesity. Adipocytes in the obese increase their cytokine production and attract macrophages, which contribute to an enhanced systemic inflammation status. On the other hand, macrophages stimulate adipose tissue remodeling by macrophagereleased MMP [69] and/or induced adipocytes-expressed MMPs [70], and may as such change adipocyte functioning.

Several other studies indicate a link between the ECM and weight regulation. Knocking-out collagen VI in the ob/ob mouse decreased body weight due to reduced fat mass at young age [16]. SPARC-null mice that exhibit increased adiposity [71] display a strong influence on the ECM conversion from a fibronectin-rich stroma to a laminin-rich basal lamina [72]. Human proof comes from drug treatment. HIV 1-infected patients receiving protease inhibitors as anti-viral therapy often develop peripheral fat wasting with difficulties in adipogenesis and fat accumulation [73]. This treatment was shown to change the activity of the endogenous proteases MMP2 and MMP9 as well as of other processing enzymes [74]. It suggests that adipogenesis and adipocyte stability may be affected by interfering with ECM dynamics. At the epidemiological level, increased plasma concentrations of MMP2 and MMP9 have been reported in obese adults [75], and increased levels of MMP9 and TIMP1 in obese children [76]. Plasma levels of TIMP1 have been found to be associated with adiposity in humans [42]. A genetic study with polymorphisms in the promoter region of the MMP1 gene among Korean subjects resulted in a significant association with BMI [77].

\section{Summary}

Although many observations are from in vitro experiments, it seems reasonable to state that two phases can be distinguished during adipogenesis. In the first phase, preadipocytes become committed to the storage of triglycerides. Synthesis of laminar collagens and of other components of the basal lamina is increased while the network of fibrillar collagens around the cell is maintained. In this phase, blocking prolyl-4-hydroxylase prevents differentiation and triglyceride storage. Mediated by a complex set of processing enzymes of which the activity is neatly regulated, the developing cell becomes embedded in the basal lamina. During the second phase, the adipocyte accumulates vast amounts of triglycerides accompanied by a change in cell shape and cell growth. Traction forces between cell and the surrounding meshwork mediated by the ECM are necessary for this process to occur. A situation is reached in which the fibrillar network functions as an outer skeleton protecting the adipocyte from mechanical disruption, and in which the laminar scaffold reduces external forces by spreading them over the tissue. Consequently, mature adipocytes spend considerable energy in maintaining and renewing their fibrillar network. ECM formation is stimulated by insulin through the transcriptional up-regulation of genes for processing enzymes. Further, being the source of pyruvate, glucose supports collagen synthesis via stimulation of the prolyl-hydroxylase/PDI complex. Other control conditions are the redox status and the supply of oxygen. In obesity, hypoxia may negatively influence ECM maintenance leading to ECM instability, cell death, and the attraction of macrophages. Alternatively, hypertrophy of adipocytes may be directly linked to ECM instability. Loss of fat mass from adipocytes during calorie restriction seems limited. This may be the consequence of the stress build-up between the shrinking cell volume and the rigid ECM, but this hypothesis still needs experimental proof. It is clear, however, that the ECM plays an important and often ignored role in adipocyte development and function and as such in lipid metabolism, weight regulation, and obesity.

Acknowledgment We thank Dr. J. Broers for his assistance in immunohistology of (pre)adipocytes.

Open Access This article is distributed under the terms of the Creative Commons Attribution Noncommercial License which permits any noncommercial use, distribution, and reproduction in any medium, provided the original author(s) and source are credited.

\section{References}

1. Pierleoni C, Verdenelli F, Castellucci M, Cinti S (1998) Fibronectins and basal lamina molecules expression in human subcutaneous white adipose tissue. Eur J Histochem 42:183-188

2. Aratani Y, Kitagawa Y (1988) Enhanced synthesis and secretion of type IV collagen and entactin during adipose conversion of 3T3-L1 cells and production of unorthodox laminin complex. J Biol Chem 263:16163-16169

3. Nakajima I, Yamaguchi T, Ozutsumi K, Aso H (1998) Adipose tissue extracellular matrix: newly organized by adipocytes during differentiation. Differentiation 63:193-200

4. Alvarez-Llamas G, Szalowska E, de Vries MP, Weening D, Landman K, Hoek A, Wolffenbuttel BH, Roelofsen H, Vonk RJ (2007) Characterization of the human visceral adipose tissue secretome. Mol Cell Proteomics 6:589-600

5. Kratchmarova I, Kalume DE, Blagoev B, Scherer PE, Podtelejnikov AV, Molina H, Bickel PE, Andersen JS, Fernandez MM, Bunkenborg J, Roepstorff P, Kristiansen K, Lodish HF, Mann M, Pandey A (2002) A proteomic approach for identification of secreted proteins during the differentiation of 3T3-L1 preadipocytes to adipocytes. Mol Cell Proteomics 1:213-222

6. Wang P, Mariman E, Keijer J, Bouwman F, Noben JP, Robben J, Renes J (2004) Profiling of the secreted proteins during 3T3-L1 adipocyte differentiation leads to the identification of novel adipokines. Cell Mol Life Sci 61:2405-2417

7. Chen X, Cushman SW, Pannell LK, Hess S (2005) Quantitative proteomic analysis of the secretory proteins from rat adipose cells 
using a 2D liquid chromatography-MS/MS approach. J Proteome Res 4:570-577

8. Aoki N, Jin-no S, Nakagawa Y, Asai N, Arakawa E, Tamura N, Tamura T, Matsuda T (2007) Identification and characterization of microvesicles secreted by 3T3-L1 adipocytes: redox- and hormone-dependent induction of milk fat globule-epidermal growth factor 8-associated microvesicles. Endocrinology 148:3850-3862

9. Molina H, Yang Y, Ruch T, Kim JW, Mortensen P, Otto T, Nalli A, Tang QQ, Lane MD, Chaerkady R, Pandey A (2009) Temporal profiling of the adipocyte proteome during differentiation using a five-plex SILAC based strategy. J Proteome Res 8:48-58

10. Zvonic S, Lefevre M, Kilroy G, Floyd ZE, DeLany JP, Kheterpal I, Gravois A, Dow R, White A, Wu X, Gimble JM (2007) Secretome of primary cultures of human adipose-derived stem cells: modulation of serpins by adipogenesis. Mol Cell Proteomics 6:18-28

11. Lim JM, Sherling D, Teo CF, Hausman DB, Lin D, Wells L (2008) Defining the regulated secreted proteome of rodent adipocytes upon the induction of insulin resistance. J Proteome Res 7:1251-1263

12. Adachi J, Kumar C, Zhang Y, Mann M (2007) In-depth analysis of the adipocyte proteome by mass spectrometry and bioinformatics. Mol Cell Proteomics 6:1257-1273

13. Roelofsen H, Dijkstra M, Weening D, de Vries MP, Hoek A, Vonk RJ (2009) Comparison of isotope-labeled amino acid incorporation rates (CILAIR) provides a quantitative method to study tissue secretomes. Mol Cell Proteomics 8:316-324

14. Wang P, Bouwman FG, Mariman EC (2009) Generally detected proteins in comparative proteomics-a matter of cellular stress response? Proteomics 9:2955-2966

15. Iyengar P, Espina V, Williams TW, Lin Y, Berry D, Jelicks LA, Lee H, Temple K, Graves R, Pollard J, Chopra N, Russell RG, Sasisekharan R, Trock BJ, Lippman M, Calvert VS, Petricoin EF 3rd, Liotta L, Dadachova E, Pestell RG, Lisanti MP, Bonaldo P, Scherer PE (2005) Adipocyte-derived collagen VI affects early mammary tumor progression in vivo, demonstrating a critical interaction in the tumor/stroma microenvironment. J Clin Invest 115:1163-1176

16. Khan T, Muise ES, Iyengar $\mathrm{P}$, Wang ZV, Chandalia M, Abate N, Zhang BB, Bonaldo P, Chua S, Scherer PE (2009) Metabolic dysregulation and adipose tissue fibrosis: role of collagen VI. Mol Cell Biol 29:1575-1591

17. Chu ML, Conway D, Pan TC, Baldwin C, Mann K, Deutzmann R, Timpl R (1988) Amino acid sequence of the triple-helical domain of human collagen type VI. J Biol Chem 263:1860118606

18. Nakajima I, Muroya S, Tanabe R, Chikuni K (2002) Extracellular matrix development during differentiation into adipocytes with a unique increase in type V and VI collagen. Biol Cell 94:197-203

19. Green H, Meuth M (1974) An established pre-adipose cell line and its differentiation in culture. Cell 3:127-133

20. Ibrahimi A, Bonino F, Bardon S, Ailhaud G, Dani C (1992) Essential role of collagens for terminal differentiation of preadipocytes. Biochem Biophys Res Commun 187:1314-1322

21. Nandan D, Clarke EP, Ball EH, Sanwal BD (1990) Ethyl-3,4dihydroxybenzoate inhibits myoblast differentiation: evidence for an essential role of collagen. J Cell Biol 110:1673-1679

22. Nakajima I, Muroya S, Tanabe R, Chikuni K (2002) Positive effect of collagen V and VI on triglyceride accumulation during differentiation in cultures of bovine intramuscular adipocytes. Differentiation 70:84-91

23. Bouwman F, Renes J, Mariman E (2004) A combination of protein profiling and isotopomer analysis using matrix-assisted laser desorption/ionization-time of flight mass spectrometry reveals an active metabolism of the extracellular matrix of 3T3L1 adipocytes. Proteomics 4:3855-3863
24. Christiaens V, Scroyen I, Lijnen HR (2008) Role of proteolysis in development of murine adipose tissue. Thromb Haemost 99:290 294

25. Gummesson A, Hagg D, Olson FJ, Hulthe J, Carlsson LM, Fagerberg B (2009) Adipose tissue is not an important source for matrix metalloproteinase-9 in the circulation. Scand J Clin Lab Invest 69:636-642

26. Wright G, Higgin JJ, Raines RT, Steenbergen C, Murphy E (2003) Activation of the prolyl hydroxylase oxygen-sensor results in induction of GLUT1, heme oxygenase-1, and nitric-oxide synthase proteins and confers protection from metabolic inhibition to cardiomyocytes. J Biol Chem 278:20235-20239

27. Prockop DJ, Sieron AL, Li SW (1998) Procollagen N-proteinase and procollagen C-proteinase. Two unusual metalloproteinases that are essential for procollagen processing probably have important roles in development and cell signaling. Matrix Biol 16:399-408

28. Berger J, Tanzawa K, Prockop DJ (1985) Sequential cleavage of type I procollagen by procollagen $\mathrm{N}$-proteinase. An intermediate containing an uncleaved pro alpha 1(I) chain. Biochemistry 24:600-605

29. Lijnen HR, Alessi MC, Frederix L, Collen D, Juhan-Vague I (2006) Tiplaxtinin impairs nutritionally induced obesity in mice. Thromb Haemost 96:731-737

30. Crandall DL, Quinet EM, El Ayachi S, Hreha AL, Leik CE, Savio DA, Juhan-Vague I, Alessi MC (2006) Modulation of adipose tissue development by pharmacological inhibition of PAI-1. Arterioscler Thromb Vasc Biol 26:2209-2215

31. Maquoi E, Demeulemeester D, Voros G, Collen D, Lijnen HR (2003) Enhanced nutritionally induced adipose tissue development in mice with stromelysin-1 gene inactivation. Thromb Haemost 89:696-704

32. Lijnen HR, Van HB, Frederix L, Rio MC, Collen D (2002) Adipocyte hypertrophy in stromelysin-3 deficient mice with nutritionally induced obesity. Thromb Haemost 87:530-535

33. Demeulemeester D, Collen D, Lijnen HR (2005) Effect of matrix metalloproteinase inhibition on adipose tissue development. Biochem Biophys Res Commun 329:105-110

34. Lijnen HR, Maquoi E, Hansen LB, Van Hoef B, Frederix L, Collen D (2002) Matrix metalloproteinase inhibition impairs adipose tissue development in mice. Arterioscler Thromb Vasc Biol 22:374-379

35. Hida K, Wada J, Eguchi J, Zhang H, Baba M, Seida A, Hashimoto I, Okada T, Yasuhara A, Nakatsuka A, Shikata K, Hourai S, Futami J, Watanabe E, Matsuki Y, Hiramatsu R, Akagi S, Makino H, Kanwar YS (2005) Visceral adipose tissue-derived serine protease inhibitor: a unique insulin-sensitizing adipocytokine in obesity. Proc Natl Acad Sci USA 102:10610-10615

36. Motrescu ER, Blaise S, Etique N, Messaddeq N, Chenard MP, Stoll I, Tomasetto C, Rio MC (2008) Matrix metalloproteinase11/stromelysin-3 exhibits collagenolytic function against collagen VI under normal and malignant conditions. Oncogene 27:6347-6355

37. Andarawewa KL, Motrescu ER, Chenard MP, Gansmuller A, Stoll I, Tomasetto C, Rio MC (2005) Stromelysin-3 is a potent negative regulator of adipogenesis participating to cancer celladipocyte interaction/crosstalk at the tumor invasive front. Cancer Res 65:10862-10871

38. Chun TH, Hotary KB, Sabeh F, Saltiel AR, Allen ED, Weiss SJ (2006) A pericellular collagenase directs the 3-dimensional development of white adipose tissue. Cell 125:577-591

39. Filippov S, Koenig GC, Chun TH, Hotary KB, Ota I, Bugge TH, Roberts JD, Fay WP, Birkedal-Hansen H, Holmbeck K, Sabeh F, Allen ED, Weiss SJ (2005) MT1-matrix metalloproteinase directs arterial wall invasion and neointima formation by vascular smooth muscle cells. J Exp Med 202:663-671 
40. Verstappen J, Von den Hoff JW (2006) Tissue inhibitors of metalloproteinases (TIMPs): Their biological functions and involvement in oral disease. J Dent Res 85:1074-1084

41. Maquoi E, Munaut C, Colige A, Collen D, Lijnen HR (2002) Modulation of adipose tissue expression of murine matrix metalloproteinases and their tissue inhibitors with obesity. Diabetes 51:1093-1101

42. Kralisch S, Bluher M, Tonjes A, Lossner U, Paschke R, Stumvoll M, Fasshauer M (2007) Tissue inhibitor of metalloproteinase-1 predicts adiposity in humans. Eur J Endocrinol 156:257-261

43. Gerin I, Louis GW, Zhang X, Prestwich TC, Kumar TR, Myers MG Jr, Macdougald OA, Nothnick WB (2009) Hyperphagia and obesity in female mice lacking tissue inhibitor of metalloproteinase-1. Endocrinology 150:1697-1704

44. Pontius J, Wagner L, Schuler G (2003) UniGene: a unified view of the transcriptome. In: Pontius J, Wagner L, Schuler G (eds) The NCBI handbook. National Center for Biotechnology Information, Bethesda

45. Su AI, Wiltshire T, Batalov S, Lapp H, Ching KA, Block D, Zhang J, Soden R, Hayakawa M, Kreiman G, Cooke MP, Walker JR, Hogenesch JB (2004) A gene atlas of the mouse and human protein-encoding transcriptomes. Proc Natl Acad Sci USA 101:6062-6067

46. Melendez-Zajgla J, Del Pozo L, Ceballos G, Maldonado V (2008) Tissue inhibitor of metalloproteinases-4. The road less traveled. Mol Cancer 7:85

47. Voros G, Sandy JD, Collen D, Lijnen HR (2006) Expression of aggrecan(ases) during murine preadipocyte differentiation and adipose tissue development. Biochim Biophys Acta 1760:18371844

48. Wang P, Keijer J, Bunschoten A, Bouwman F, Renes J, Mariman $\mathrm{E}$ (2006) Insulin modulates the secretion of proteins from mature 3T3-L1 adipocytes: a role for transcriptional regulation of processing. Diabetologia 49:2453-2462

49. Wilsie LC, Chanchani S, Navaratna D, Orlando RA (2005) Cell surface heparan sulfate proteoglycans contribute to intracellular lipid accumulation in adipocytes. Lipids Health Dis 4:2

50. Okuno $M$, Arimoto $E$, Nishizuka $M$, Nishihara $T$, Imagawa $M$ (2002) Isolation of up- or down-regulated genes in PPARgammaexpressing NIH-3T3 cells during differentiation into adipocytes. FEBS Lett 519:108-112

51. Francois M, Richette P, Tsagris L, Raymondjean M, FulchignoniLataud MC, Forest C, Savouret JF, Corvol MT (2004) Peroxisome proliferator-activated receptor-gamma down-regulates chondrocyte matrix metalloproteinase-1 via a novel composite element. J Biol Chem 279:28411-28418

52. Wang P, Renes J, Bouwman F, Bunschoten A, Mariman E, Keijer $J$ (2007) Absence of an adipogenic effect of rosiglitazone on mature 3T3-L1 adipocytes: increase of lipid catabolism and reduction of adipokine expression. Diabetologia 50:654-665

53. MacDonald MJ (2003) The export of metabolites from mitochondria and anaplerosis in insulin secretion. Biochim Biophys Acta 1619:77-88

54. Thoms S, Gronborg S, Gartner J (2009) Organelle interplay in peroxisomal disorders. Trends Mol Med 15:293-302

55. Berra E, Benizri E, Ginouves A, Volmat V, Roux D, Pouyssegur J (2003) HIF prolyl-hydroxylase 2 is the key oxygen sensor setting low steady-state levels of HIF-1alpha in normoxia. EMBO J 22:4082-4090

56. Myllyharju J (2008) Prolyl 4-hydroxylases, key enzymes in the synthesis of collagens and regulation of the response to hypoxia, and their roles as treatment targets. Ann Med 40:402-417

57. McDonagh B, Sheehan D (2008) Effects of oxidative stress on protein thiols and disulphides in Mytilus edulis revealed by proteomics: actin and protein disulphide isomerase are redox targets. Mar Environ Res 66:193-195
58. Nardai G, Stadler K, Papp E, Korcsmaros T, Jakus J, Csermely P (2005) Diabetic changes in the redox status of the microsomal protein folding machinery. Biochem Biophys Res Commun 334:787-795

59. Tanabe Y, Koga M, Saito M, Matsunaga Y, Nakayama K (2004) Inhibition of adipocyte differentiation by mechanical stretching through ERK-mediated downregulation of PPARgamma2. J Cell Sci 117:3605-3614

60. Spiegelman BM, Ginty CA (1983) Fibronectin modulation of cell shape and lipogenic gene expression in 3T3-adipocytes. Cell 35:657-666

61. Wolf G, Chen S, Han DC, Ziyadeh FN (2002) Leptin and renal disease. Am J Kidney Dis 39:1-11

62. Lijnen PJ, Petrov VV (2003) Role of intracardiac renin-angiotensin-aldosterone system in extracellular matrix remodeling. Methods Find Exp Clin Pharmacol 25:541-564

63. Ganesan K, Tiwari M, Balachandran C, Manohar BM, Puvanakrishnan R (2008) Estrogen and testosterone attenuate extracellular matrix loss in collagen-induced arthritis in rats. Calcif Tissue Int 83:354-364

64. O'Callaghan CJ, Williams B (2002) The regulation of human vascular smooth muscle extracellular matrix protein production by alpha- and beta-adrenoceptor stimulation. J Hypertens 20:287-294

65. Halberg N, Wernstedt-Asterholm I, Scherer PE (2008) The adipocyte as an endocrine cell. Endocrinol Metab Clin North Am 37:753-768 x-xi

66. Trayhurn P, Wang B, Wood IS (2008) Hypoxia and the endocrine and signalling role of white adipose tissue. Arch Physiol Biochem 114:267-276

67. Vosseller K, Wells L, Lane MD, Hart GW (2002) Elevated nucleocytoplasmic glycosylation by O-GlcNAc results in insulin resistance associated with defects in Akt activation in 3T3-L1 adipocytes. Proc Natl Acad Sci USA 99:5313-5318

68. Renes J, Bouwman F, Noben JP, Evelo C, Robben J, Mariman E (2005) Protein profiling of 3T3-L1 adipocyte differentiation and (tumor necrosis factor alpha-mediated) starvation. Cell Mol Life Sci 62:492-503

69. Unoki H, Bujo H, Jiang M, Kawamura T, Murakami K, Saito Y (2008) Macrophages regulate tumor necrosis factor-alpha expression in adipocytes through the secretion of matrix metalloproteinase-3. Int J Obes (Lond) 32:902-911

70. O'Hara A, Lim FL, Mazzatti DJ, Trayhurn P (2009) Microarray analysis identifies matrix metalloproteinases (MMPs) as key genes whose expression is up-regulated in human adipocytes by macrophage-conditioned medium. Pflugers Arch 458:1103-1114

71. Bradshaw AD, Graves DC, Motamed K, Sage EH (2003) SPARC-null mice exhibit increased adiposity without significant differences in overall body weight. Proc Natl Acad Sci USA 100:6045-6050

72. Nie J, Sage EH (2009) SPARC inhibits adipogenesis by its enhancement of beta-catenin signaling. J Biol Chem 284:12791290

73. Kim RJ, Wilson CG, Wabitsch M, Lazar MA, Steppan CM (2006) HIV protease inhibitor-specific alterations in human adipocyte differentiation and metabolism. Obesity (Silver Spring) 14:994-1002

74. Mondal D, Larussa VF, Agrawal KC (2001) Synergistic antiadipogenic effects of HIV type 1 protease inhibitors with tumor necrosis factor alpha: suppression of extracellular insulin action mediated by extracellular matrix-degrading proteases. AIDS Res Hum Retroviruses 17:1569-1584

75. Derosa G, Ferrari I, D'Angelo A, Tinelli C, Salvadeo SA, Ciccarelli L, Piccinni MN, Gravina A, Ramondetti F, Maffioli P, 
Cicero AF (2008) Matrix metalloproteinase-2 and -9 levels in obese patients. Endothelium 15:219-224

76. Glowinska-Olszewska B, Urban M (2007) Elevated matrix metalloproteinase 9 and tissue inhibitor of metalloproteinase 1 in obese children and adolescents. Metabolism 56:799-805
77. Nho YK, Ha E, Yu KI, Chung JH, Wook NC, Chung IS, Lee MY, Shin DH (2008) Matrix metalloproteinase-1 promoter is associated with body mass index in Korean population with aged greater or equal to 50 years. Clin Chim Acta 396:14-17 